\title{
Sinema Nasional Malaysia: Pasang Surut Budaya Dalam Tiga Era
}

\author{
MOHD ERMAN MAHARAM \\ MASTURA MUHAMMAD \\ HARITH BAHARUDDIN \\ Universiti Teknologi MARA
}

\begin{abstract}
ABSTRAK
Persembahan sinematik atau filem boleh dikupas secara ilmiah dari berbagai sudut ilmu. Filem sebagai sebuah representasi umumnya dibincangkan secara terhad mewakili sesuatu wilayah sosiopolitik tertentu. Oleh itu, penulisan ini membincangkan idea Sinema Nasional bagi sinema Malaysia yang dikesan sebagai sesuatu yang bermasalah kerana hanya ditumpukan pada satu-satu filem atau terhad kepada ketetapan ciri nasional yang sempit. Dengan latar sedemikian, kajian ini mempermasalahkan dan mempersoalkan konsep Sinema Nasional Malaysia dengan hujahan, aspek-aspek sosiobudaya dan politik Malaysia sebagai satu wilayah bertindih dengan institusi budaya serantau melalui pengalaman merantau. Bagi penulisan ini, Malaysia dijejaki secara longue durée kerana estetika sinematik bukan sahaja menganjurkan kaitan kebudayaan serantau, malah tidak berpegang pada sesuatu yang spesifik kerana ianya bereaksi kepada keadaan sosio-politik semasa. Artikel ini mengambil pendekatan diskusi (discourse) dan pasang surut budaya dengan sokongan analisis tekstual dalam membincangkan perubahan interpretasi ruang budaya dari tiga fasa berbeza yang dibahagikan kepada era hitam-putih (1950s-1960s), era independen (1970s-1990s), dan era digital (2000an hingga kini). Filem-filem yang dipilih akan dikupas dengan kaitan isu-isu ini. Berdasarkan analisa filem-filem ini, penulisan ini mencadangkan idea sinema nasional Malaysia harus menerima idea yang sinema nasional tidak homogeny, tetapi, ianya kompleks dan cair kerana idea sinema nasional untuk sebuah negara seperti Malaysia sentiasa berubah bergantung kepada iklim politik yang sering diperbaharui oleh warganya.
\end{abstract}

Kata kunci: Sinema Nasional, identiti budaya, merantau, sinematik, rasa kepunyaan.

\section{Malaysian National Cinema: Cultural Tides in Three Different Eras}

\begin{abstract}
The discussion on film and its cinematic representation is appropriated in the form by a variety of perspectives. Popularly, the discussion on 'film as representation' is extensively contextualized into specific sociocultural political territories. Thus, the notion of Malaysian national cinema is viewed as problematic because of the formulation of such narrow concepts as it is confined to a conventional set of characters and using specific films for analysis. Against this backdrop, this study problematizes and questions the conventional concept of Malaysian National Cinema with the argument that the socio-cultural and political aspects of Malaysia as a region are imbricating other(s) regional cultural institutions through the merantau or itinerant experience. In this paper, Malaysian films are acknowledged as longue durée as cinematic aesthetics are not only built within a specific regional culture, nor demarcated within a specific classification as they coincide within the current state of socio-political changes. Employing discourse analysis and cultural tidalectics, underpinned by textual analysis, this study discusses the changes of culture and its interpretation in three periods of Malaysian cinema: the black-and-white (1950s-1960s), independence (1970s-1990s) and digital period (2000 to present). The selected films will be discussed in relation to these issues. Based on the films analysed, this paper proposes that the idea of national cinema of Malaysia should acknowledge the idea that
\end{abstract}


national cinemas are not homogenous, instead, it is complex and fluid because the ideas of national cinema for a country like Malaysia are constantly changing, depending on the political climate that is often shifted by its citizens.

Keywords: National cinema, cultural identity, merantau, cinematic, sense of belonging.

\section{PENGENALAN}

Idea Sinema Nasional umumnya masih popular sebagai sandaran perbincangan pengajian sinema dan filem Malaysia. Persoalan utama penulisan ini berkisar mengenai apa yang dimaksudkan dengan Sinema Nasional Malaysia. Kami tidak bercadang untuk memberi suatu ketetapan yang ketat dan sempit tetapi lebih kepada memberi keadilan kepada sinema Malaysia dengan mengupas unsur-unsur sinematik filem-filem pilihan melalui pendekatan konseptual dengan sewajarnya. Selain itu, artikel ini akan mengupas perubahan sifat kepunyaan atau rasa termilik (sense of belonging) dalam filem-filem tempatan yang seiring dengan evolusi Malaysia sebagai sebuah negara bangsa. Pada dasarnya, Sinema Nasional dicadangkan sebagai idea yang perlu dilihat secara menyeluruh dalam konteks nasional itu sendiri, milikan konstruktif yang sesuai dengan aliran mobiliti sosial penduduk.

Idea Sinema Nasional bagi sinema Malaysia sebenarnya bermasalah jika hanya dibincangkan dengan mengupas nilai tertentu pada satu-satu filem tertentu secara preskriptif dan adakalanya superfisial seperti melihat lambang-lambang tertentu dan bahasa pertuturan seperti cadangan Chang (2017) serta Fatimah dan Nur Afifah (2018). Transformasi dan maju mundur atau pasang surut budaya masyarakat dari mula terbentuknya Malaysia hingga kini hampir pasti boleh dibaca dari kualiti representasi sinematik di beberapa persimpangan pembangunan nasional. Malah, jika dilihat dari aspek terma ekonomi, penilaian secara tekstual, pemameran dan penontonan, mahupun pendekatan-pendekatan secara kritikal (Higson, 1989), filem-filem dari negara ini secara konsisten melangkaui wilayah nasional kerana pertindihan budaya dan sentiasa berinteraksi dengan keadaan sosio-politik serantau.

Seperkara lagi, gagasan meletakkan ras (race) dan bahasa sebagai laras utama sinema nasional Malaysia dipercayai sebagai tidak sesuai kerana identiti tunggal berlandaskan bahasa pertuturan yang digunakan di dalam filem boleh disanggah sebagai gagasan etnonasionalisme yang dangkal dan masih berteraskan "perkauman yang sempit" (Syed Husin Ali dipetik oleh Suhana et al., 2012). Benar bahasa Melayu adalah Bahasa Kebangsaan Malaysia, namun bahasa seharian yang dituturkan oleh khalayak dan di dalam filem tidak terhad kepada satu pertuturan yang standard. Menurut Shamsul A. B. seperti yang dipetik oleh Norman (2013), konsep ras yang diwarisi dari era kolonial membentuk ideologi politik bersandarkan etnik dan idea berkaitan Melayu dan KeMelayuan (Malay-Malayness) telah dirangka oleh historiografi kolonial yang seterusnya digunapakai oleh sejarawan pasca-kolonial Nusantara tanpa melihatnya secara kritikal. Oleh itu, objektif utama kajian ini adalah untuk mengetengahkan kaitan idea serta dasar politik negara dengan identiti budaya di dalam filem yang mempunyai kaitan dan membentuk pemaparan peralihan budaya yang cair. Selain itu, perbincangan konsep mobiliti khususnya "merantau" yang menyumbang kepada perubahan identiti budaya nasional hampir tidak disentuh oleh pengkaji-pengkaji lain apabila membincangkan representasi budaya dalam filem-filem dari Sinema Malaysia. Justeru itu, objektif kedua penulisan ini adalah untuk mengangkat konsep merantau dalam pemaparan sinematik yang mempengaruhi budaya masyarakat negara ini seperti yang direpresentasikan di dalam filem-filem pilihan. 
Penulisan ini berkongsi pendapat dengan Asiah (2006) yang menegaskan bahawa idea Sinema Nasional berkait rapat dengan permasalahan konsep bangsa (nation) dan nasionalisme. Seperti cadangan Higson (2000), Asiah menyarankan yang perjalanan sejarah filem Malaysia perlu diberi perhatian apabila membincangkan idea ini kerana Malaysia sebagai entiti nasional juga berubah sebagai sebuah institusi dan wilayah politiknya. Persoalan di antara dua istilah nation dan nasionalisme tidak sepatutnya menjadi polemik, namun, ianya berkemungkinan menjadi beban apabila istilah negara-bangsa (nation-state), bangsa (nation) dan nasional itu disalah ertikan. Perkara ini akan dibincangkan dengan lebih terperinci dalam bahagian seterusnya dan menerusi analisa filem Sri Mersing (1961), Keluarga Si Comat (1975) dan Nasi Lemak 2.0 (2011).

\section{TINJAUAN LITERATUR}

Idea sinema nasional pada mulanya diketengahkan dengan merujuk kepada sinema British dan ianya diakui mempunyai kelemahan kerana sifatnya yang abstrak dan tidak sepatutnya dirujuk sebagai sesuatu takrifan atau pengkelasan yang ideal (Higson, 2000). Pertimbangan semula yang dibincangkan oleh Higson adalah merujuk kepada idea "komuniti bayangan" oleh Anderson (1983) serta kekhilafan mengenai istilah nasional yang difahami sebagai telah lengkap dan digariskan dengan jelas.

Dalam mempertikaikan permasalahan gagasan "komuniti bayangan" Anderson, Higson (2000) menegaskan yang gagasan berkenaan adalah sulit kerana ianya tidak membenarkan perbincangan melangkaui sempadan geopolitik dan menghadkan rasa termilik dengan limitasi politik. Beliau menegaskan, masalah dalam membincangkan identiti sinema nasional dalam konteks ini adalah batasan wilayah budaya yang ditetapkan oleh identiti nasional yang tidak terbuka dan ditakrifkan menerusi kesinambungan komuniti yang dihadkan. Tambah beliau, ia gagal mengambil kira perbezaan dan kepelbagaian budaya yang menandai penduduk sesebuah negara-bangsa selain dari mengenepikan keanggotaan nasional yang bertaburan secara geografik. Filem-filem kontemporari Malaysia seperti Crossroads: One Two Jaga (2018) dan, Interchange (2016) jelas menyanggah "komuniti bayangan" kerana memiliki kualiti persembahan sinematik dan keanggotaan nasional yang melangkaui sempadan negara.

Seterusnya, Higson dalam artikel yang sama mencadangkan yang identiti nasional bukanlah sesuatu yang telah sempurna. Penulisan ini bersetuju dengan apa yang dihujahkan oleh Higson (1989) kerana hingga kini, dunia masih terus menemukan negara-negara baru, sempadan-sempadan yang antara lain memisahkan penduduk setempat dan kedaulatan sesebuah negara masih terus dipertikaikan seperti apa yang sedang dilalui oleh negara-negara serantau termasuk Malaysia. Higson antara lainnya memberikan dua hujah: Pertamanya, sinema sesebuah negara tidak memiliki autonomi terhadap industri filem dan budaya kerana perfileman bermula dengan gabungan inisiatif serantau, nasional dan transnasional. Perkara ini jelas dalam konteks sejarah sinema Malaysia kerana sinema negara ini bermula di Singapura dan diraikan oleh penonton dan pengkarya serantau. Keduanya, Higson mengetengahkan permasalahan pengedaran dan resepsi filem-filem yang sememangnya dihasilkan dengan sasaran yang melangkaui sempadan nasional. Menjejaki isu ini, kebanyakan filem-filem P. Ramlee umpamanya jelas diketahui dibuat dengan pertimbangan dan diterima oleh penonton serantau (lihat Kahn 2006; Anwar 1988; Pané 1953). Malah, banyak filem kontemporari yang dihasilkan dengan dana serta matlamat melangkaui 
sempadan nasional akan keciciran dalam perbincangan identiti nasional dalam persembahan sinematik oleh pembikin filem warganegara Malaysia yang berkenaan.

Seperkara yang menarik dalam pertimbangan semula Sinema Nasional oleh Higson (2000) adalah beliau menjelaskan yang "kepelbagaian budaya" dan "perihal nasional" sesungguhnya bergantung kepada polisi atau dasar sesebuah negara. Aspek ini menjadi teras kepada artikel ini kerana wajah serta identiti sosio-budaya dan masyarakat tempatan yang direpresentasikan melalui filem sentiasa berevolusi terhadap situasi sosio-politik tempatan dan serantau, yang berkait dengan perkembangan teknologi komunikasi, dan kemudahan mobiliti yang dipertingkat secara berterusan. 'Budaya Nasional' menurut Stuart Hall seperti yang dipetik oleh Wan Aida (2011) adalah sesuatu yang sangat moden di mana identifikasi serta kesetiaan kepada kebudayaan tradisi diterapkan secara beransur-ansur. Kaitan kebudayaan serantau dan perbezaan etnik walau bagaimanapun, secara perlahan-lahan disisipkan, bergantung kepada asas politik dan tafsiran identiti kebudayaan moden negara tersebut. Perubahan dasar tertentu umpamanya, memberi kesan kepada filem-filem dan boleh dilihat melalui perubahan dalam sinema tempatan sebelum dan selepas era Konfrontasi (1963-1966) dan pelaksanaan Dasar Ekonomi Baru (DEB) (1970-1990).

Istilah atau konsep ras, bangsa, negara dan negara-bangsa kerap bertembung dan bercanggah apabila menjadi topik perdebatan dalam menentukan kuasa politik Malaysia. Oleh itu, ianya banyak mempengaruhi kecelaruan dalam masyarakat. Kumpulan-kumpulan yang mempunyai kaitan secara langsung mahupun tidak dalam penerbitan filem juga terlibat dalam polemik ini dan seterusnya mendominasi pandangan popular mengenai sinema nasional yang boleh dianggap sebagai tautologi idea yang disengajakan (Norman, 2018).

Menurut Malik (1996), konsep bangsa yang diperkenalkan pada lewat abad ke 18 adalah berbeza dengan apa yang difahami hari ini. Pada ketika itu, konsep bangsa membenarkan individu mengidentifikasikan diri secara kolektif melangkaui had sempit sesuatu komuniti dan setiap individu atau kumpulan komuniti, adalah sebahagian daripada masyarakat universal. Bangsa pada awalnya ditakrifkan sebagai plebisit atau pungutan suara umum (daily plebiscite) di mana bangsa diekspresikan sebagai kedaulatan kolektif oleh sesuatu kumpulan manusia secara umum. Dalam konteks ini, bangsa adalah kesepakatan bersama yang menolak keistimewaan tertentu dan tidak menekankan kepada etnik yang spesifik serta tidak memberi penekanan kepada kesinambungan sejarah. Namun, setelah revolusi di Eropah dan Amerika, konsep bangsa berubah kepada bangsa yang bersandarkan 'revolusi demokratik' (revolutionary-democratic) dan mengetengahkan idea negara-bangsa dan 'kebangsaan' (nationhood) yang melibatkan kewarganegaraan, penglibatan serta pilihan masyarakat.

Kemajuan sebagai negara moden, perubahan ideologi politik dan ekonomi dunia pada pertengahan abad ke 19, menurut Malik (1996), adalah antara faktor utama yang menyumbang kepada transformasi konsep bangsa yang diterima pada hari ini. Projek menginstitusikan pentadbiran dan pengawalan negara adalah perkara baharu. lanya berbeza dengan yang diamalkan sebelum zaman pencerahan (the Enlightenment). Industrialisasi dan kemajuan dalam bidang pendidikan dikesan sebagai pemangkin kepada perubahan yang kini menjadikan negara sebagai penentu kepada manusia, sama ada sebagai subjek, atau warganegara. Transformasi ini memberi kesan kepada hal memahami perkaitan antara ras dan budaya. Jika pada awalnya idea dari era pencerahan yang menghebahkan universalisme membangkitkan diskusi mengenai ras, kegagalan pandangan kosmopolitan menggerakkan gagasan budaya yang bersifat khusus kepada sesuatu kumpulan tertentu. Fenomena ini tidak hanya berlaku di negara pasca-kolonial seperti Malaysia, malah di negara-negara lebih moden 
di Eropah dan Amerika. Menurut Mahyuddin dan Lee (2015), 'bangsa' yang pada asalnya merujuk kepada 'etnik' telah melalui proses transformasi. Bersandarkan hujahan Todorov yang mencadangkan istilah ras kini telah memonopoli istilah budaya, Malik merumuskan yang rasa termilik dalam konteks nasional tidak seharusnya dinilai dari kewarganegaraan dan juga tempat kelahiran, tetapi melalui kualiti memiliki intipati kepunyaan dan rasa termilik kepada entiti nasional. Contoh mudah, generasi kedua migran yang diberi kelayakan warganegara oleh negara kelahiran tetap mempunyai rasa kepunyaan dan termilik yang tinggi kepada negara asal ibubapa.

Umumnya, identiti budaya sesuatu masyarakat sering berubah, cair (fluid) dan perubahan yang berlaku sejak dari mula manusia hidup bertamadun hingga kini jelas menyokong konsep kemenjadian (becoming) di mana sesuatu yang telah sedia wujud mempunyai sifat untuk terus berkembang secara beransur-ansur. Bhabha (1990), mencadangkan yang bangsa adalah sistem budaya melambangkan kehidupan sosial berbanding disiplin politik sosial. Begitu juga dengan apa yang diterima sebagai karakteristik nasional Malaysia. Sebagai contoh, nilai karakteristik Malaysia berubah dari nama Persekutuan Tanah Melayu, ke Malaya dan seterusnya Malaysia. Malah, perubahan komposisi demografik penduduk, kuasa ekonomi dan politik juga menyumbang kepada proses kemenjadian Malaysia hingga hari ini.

Idea Sinema Nasional Malaysia menjadi penting apabila terma 'nasional' itu melibatkan isu berkenaan produksi, pengedaran dan penontonan serta ciri yang membentuk kolektiviti nasional (Mahyuddin \& Lee, 2015). Di samping itu, idea Sinema Nasional juga memberi ruang untuk kita memahami bagaimana sesuatu bangsa memilih mewakili diri mereka dalam filem dan boleh menjadi instrumen untuk menginterogasi ideologi membina bangsa dalam filem (Higbee, 2007).

\section{KONTEKS KAJIAN}

Untuk memahami sinema dalam kerangka komuniti politik tidak semudah yang disangka. Sejarah pembangunan negara Malaysia mempunyai liku-likunya yang tersendiri. Namun, sebagai medium seni dan hiburan yang ikonik, sinema boleh digunakan untuk memahami wacana popular berkenaan identiti, budaya dan realiti sosial (Norman Yusoff, 2013). Sebagai sebuah entiti nasional, negara bekas jajahan ini melalui beberapa persimpangan politik dan nasionalisasi sebelum dikenali sebagai Malaysia. Tanahair bagi masyarakat berbagai etnik ini jika selusuri dari masa lampau, tidak serasi dengan jajahan dan berpemerintahan sendiri (Scott, 2009).

Dari sudut pembikinan mahupun pendedahan filem kepada khalayak tempatan, ianya menuntut pertimbangan aspek penontonan yang berubah mengikut tuntutan pembangunan negara. Seperti yang telah dinyatakan, kami klasifikasikan era sinema tempatan kepada era filem hitam-putih, independen, dan digital. Tiga era ini tidak hanya memperlihatkan perubahan teknologi perfileman, malah mampu dijadikan pemisah pergerakan budaya melalui persepsi ruang politik dan budaya yang diraikan di dalam filem-filem berkenaan.

\section{Era hitam-putih (1930an - 1960an)}

Membincangkan akar Sinema Malaysia perlu melibatkan Sinema Singapura. Singapura adalah pusat komersial yang menjadi tumpuan penerbit-penerbit filem komersial apabila teknologi perfileman sampai di rantau ini. Pada awalnya, penerbit-penerbit dari Shanghai hanya menghasilkan filem bagi pengedaran di Tanah Besar China. Selepas itu, pengusaha bersama 
pengarah menghasilkan filem-filem untuk penonton tempatan. Dari studio-studio Jalan Ampas Singapura (selain Bandung di Jawa), bermulanya masyarakat setempat direpresentasikan dalam medium filem. Studio Merdeka hanya bertapak di Kuala Lumpur pada 1960. Penonton dan istilah "tempatan" pada era filem hitam-putih ini, tidak seperti hari ini kerana kini ruang budaya telah disempitkan oleh ketetapan politik kenegaraan. Filem-filem seperti Raden Mas (1959) dan Bayangan Di Waktu Fajar (1962) pada awalnya menghubungkan manusia di rantau ini kerana kualiti representasi yang ditayangkan tidak lari jauh dari pengalaman kehidupan seharian masyarakat. Secara ringkas, penonton mudah untuk mengaitkan diri mereka dengan kehidupan di dalam filem-filem ini berbanding filemfilem yang dihasilkan dari tempat-tempat lain. Perkara ini adalah penting bagi Sinema Malaysia, namun jika had sempadan politik moden dijadikan sebagai ukuran, hanya sejumlah kecil yang layak dibincangkan bersama. Ini kerana, Singapura hanya bersama Malaysia dari tahun 1963 hingga 1965 selain dari penubuhan Indonesia pada 1950 yang menutup pasaran bagi filem-filem tempatan secara perlahan-lahan. Maka, tidak hairanlah tuntutan hak kepunyaan eksklusif Singapura terhadap 91 filem-filem hitam-putih pada 2014 melalui penyenaraian di Memory of the World Asia-Pacific Regional Register, Unesco, tidak mendapat bantahan dari Malaysia.

Era yang digelar era emas (1950an - 1960an) filem-filem berbahasa Melayu yang kini menjadi nostalgia masih kekal dibincangkan di Malaysia. Kedudukan sosio-budaya Melayu di dalam ruang sinematik diperkukuhkan dengan kemunculan pengarah-pengarah Melayu seperti P. Ramlee, M. Amin, Hussein Haniff, Jamil Sulong sebagai pengarah, editor, pelakon dan ramai lagi yang mula menerapkan elemen keMelayuan secara lebih mendalam di dalam filem-filem arahan mereka. Menurut Kahn (2006), P. Ramlee contohnya merupakan antara pengarah Melayu yang gemar memfokuskan isu berkisarkan permasalahan masyarakat Melayu atau sepertimana yang disebut sebagai "newly emerging Malay identity" melalui filem-filem seperti Penarek Becha (1955), Anakku Sazali (1956), dan Seniman Bujang Lapok (1961). Manakala Jamil Sulong dan Hussein Hanif pula adalah antara pengarah-pengarah Melayu yang mengangkat cerita-cerita yang diadaptasi dari cerita-cerita rakyat.

Namun, sepertimana yang disebut oleh Barnard (2010), walaupun intipati filem-filem ini terarah kepada sosio-budaya Melayu, penonton tidak melihatnya sebagai representasi yang mengangkat kaum Melayu. Bagi era ini, populariti P. Ramlee yang kini diangkat sebagai Seniman Agung Malaysia mengaburi ramai tokoh lain seperti mentor beliau sendiri L. Krishnan yang merepresentasikan kepelbagaian budaya minoriti yang merentasi sempadan politik dan kekuatan mitos dalam masyarakat seperti yang dipaparkan dalam filem Tas Tangan Wanita (1952), Raden Mas (1959), dan Keris Sempena Riau (1961). Selain itu, pengarah lain seperti Hussein Haniff yang menunjukkan kekirian melalui kritikan terhadap feudalisme juga semakin dilupakan. Tidak dinafikan, terdapat banyak judul dari P. Ramlee sendiri yang mengandungi persoalan ruang budaya masyarakat cuma untuk bagi perbincangan di sini, kami memilih untuk mengambil persembahan Salleh Ghani, Sri Mersing (1961). Alasan kami, filem ini tidak hanya menyentuh ruang budaya secara sinematik tetapi ianya juga mengangkat topik mobiliti masyarakat melalui konsep merantau yang membawa kepada persoalan rasa kepunyaan dan termilik individu.

\section{2. $\quad$ Era independen (1970an - 1990an)}

Dasar Kebudayaan Kebangsaan 1971 digagaskan untuk memelihara identiti budaya Malaysia sepatutnya mempromosikan integrasi nasional dan perpaduan serta mengekalkan keharmonian kaum (Syed Hussein Alatas, 1985). Namun, pandangan yang berlawanan dan 
menuntut budaya etnik Melayu sebagai peneraju identiti budaya nasional tunggal juga kuat dilaungkan (Zainal, 1985).

Menurut Khoo (2006), era independen bermula pada 1974 di mana pembentukan sinema nasional Malaysia lebih bersifat entnosentrik Melayu. Bagi Hatta (1997) pula, ianya mula berlaku pada 1974 hingga 1986 walaupun syarikat produksi independen pertama adalah Gabungan Artis Filem Company (Gafico) ditubuhkan pada 1967. Perkembangan industri perfileman yang dibincangkan pada bahagian ini dilihat menjadi penanda aras yang paling awal dalam usaha mengukuhkan konsep 'sinema nasional' yang dilihat lebih cenderung meraikan satu karya seni seperti filem berteraskan sesuatu etnik atau kaum. Sinema Malaysia, pada era ini, menyaksikan pembentukan syarikat-syarikat independen Bumiputera yang dimiliki oleh golongan Melayu (van der Heide, 2002). Perkara ini selari dengan perkembangan politik yang mempromosikan pembangunan masyarakat Melayu Malaysia seperti Dasar Ekonomi Baru (1970). Ini sekaligus merumitkan maksud atau definisi 'nasional sinema' pada era kontemporari kini.

Takrifan filem-filem independen umpamanya, tidak sekadar satu istilah yang mewakili filem-filem yang dihasilkan dengan bajet rendah, dan tanpa suntikan dana dari studio besar semata-mata tetapi juga merangkumi ideologi serta prinsip-prinsipnya yang tersendiri di mana ianya ditakrifkan sebagai 'berbeza' dan kontradik dari segala bentuk yang biasa dipersembahkan dalam arus perdana. Menurut Levy (1999);

[...] "independent" meant opposition to the dominant media. On several fronts: technological (amateur $8 \mathrm{~mm}$ and $16 \mathrm{~mm}$ instead of professional $35 \mathrm{~mm}$ formats); institutional (interpersonal and communal versus corporate production); aesthetic (original and avant-garde against the conventional and generic); economic (love of film rather than love of money was the prime motivation); and political (exploring marginal and disenfranchised cultures instead of focusing on the culturally dominant (p. 5).

Selain Gafico, syarikat-syarikat penerbitan seperti PERFIMA dan Sari Actor ditubuhkan oleh usahasama artis-artis tempatan seperti P. Ramlee, Sarimah, Jaafar Abdullah, Jins Shamsudin dan bantuan ahli perniagaan seperti H.M Shah. Tahun 1975 menyaksikan Deddy M. Borhan dari Sabah menubuhkan Sabah Film Production dan menerbitkan Keluarga Si Comat (1975) dan telah membuka lembaran baru kepada industri perfileman Malaysia. Dari pandangan van der Heide (2002),

Keluarga Si Comat by Sabah Filem, [...] was the breakthrough in the Malaysian film industry after the decline of the studio system. This light comedy, shot in colour, resulted in the return of audiences to the cinema.

Selepas kejayaan Sabah Film Productions, muncul pula syarikat Bumiputera lain seperti Perfima, Syed Kechik Productions, Indra film Productions. Baharudin Latif (1989) melihat perubahan arus ini memberi kesan kepada aspek penontonan sinema tempatan. Penonton Melayu kembali ke pawagam untuk menonton filem yang dihasilkan oleh produksiproduksi independen ini. Industri perfileman kembali memberi pulangan yang menguntungkan dan memberi keyakinan kepada bank-bank dan agensi-agensi kerajaan seperti Majlis Amanah Rakyat (MARA), Urban Development Authority of Malaysia (UDA), dan 
Perbadanan Nasional Berhad (PERNAS) untuk melabur dan memberi bantuan kewangan kepada syarikat-syarikat ini.

Filem-filem seperti Keluarga Si Comat (1975), Tuan Badul (1979) dan Gila-Gila (1979) juga agak jelas mengangkat kehidupan masyarakat Melayu sebagai 'orang kaya baru' yang berjaya dalam bidang perniagaan. Justeru, untuk membincangkan konsep penghijrahan dan perubahan identiti representasi sedemikian, kami memilih filem Keluarga Si Comat sebagai filem kajian. Filem awal era independen ini bukan sahaja berjaya mengembalikan penonton ke pawagam ketika itu, malah cuba merepresentasikan masyarakat marginal dari Sabah, Borneo. lanya boleh dianggap sebagai contoh yang baik bagaimana kumpulan masyarakat yang sebelum ini agak terpinggir, dinasionalisasikan melalui filem, dalam genre komedi.

Kemunculan teknologi digital bagi penerbitan filem di penghujung tahun 1990an menghasilkan satu lagi kategori independen. Bagi perbincangan ini, kami namakan sebagai Era digital. Filem dari era ini dianggap cenderung untuk memaparkan gaya hidup dan kebudayaan kepelbagaian etnik yang wujud di Malaysia berbanding dengan filem-filem Melayu aliran utama yang secara tidak langsung memaparkan dominasi kaum. Filem-filem ini mengangkat nilai-nilai budaya seperti dialek bahasa yang tidak hanya memfokus kepada bahasa standard malah lebih kepada prinsip dan semangat 'kebebasan' atau independen itu sendiri. Filem-filem ini dihasilkan berdasarkan motivasi artistik seorang pengarah atau karyawan filem secara personal berbanding keinginan untuk mendapat pulangan dari jualan tiket.

\section{Era digital (2000 - hingga sekarang)}

Perkembangan teknologi sentiasa memberi kesan filem dan sinema. Agak jelas, persembahan filem muncul dan lahir dari perkembangan teknologi. Teknologi memberi kesan kepada cara sesebuah filem dihasilkan di mana dengan teknologi yang semakin canggih dan semakin murah, penghasilan sesebuah filem semakin mudah dan penglibatan pengkarya juga semakin ramai kerana teknologi membuka ruang yang lebih besar kepada pengkarya mahupun pelabur industri filem. Menurut Palfrey dan Gasser (2008), teknologi digital telah merubah kehidupan manusia dan bagaimana mereka berhubung antara satu sama lain di antara mereka. Era digital perfileman Malaysia menurut Fuziah Kartini et al. (2018) adalah;

[...] tempoh masa dan persekitaran manusia menggunakan teknologi baru sebagai landasan atau alat bagi mempercekapkan proses berfikir, membuat keputusan dan bertindak balas terhadap manusia dan kehidupannya (p. 2).

Impak kepada kepesatan era digital ini adalah kemunculan karyawan muda yang memberi keyakinan kepada pelabur bereksperimen dengan pengarah filem generasi baru yang muncul secara independen. Menurut McKernan (2005),

...today's digital technology has democratized this most powerful form of storytelling, making it affordable enough for practically anyone to use ( $\mathrm{p}$. preface).

Generasi baru ini bukan sahaja membawa idea dan gaya visual yang segar tetapi juga membawa bersamanya pandangan yang menggugat kepercayaan dan nilai sosio-politik generasi lama yang sebelum ini agak sensitif untuk diketengahkan. Hal ini berlaku di seluruh dunia dan Malaysia, tidak terkecuali. Era ini menyaksikan kemunculan pengarah-pengarah 
baharu yang berkarya menggunakan kamera video digital dalam penghasilkan karya-karya mereka. Khoo (2007) umpamanya, menggelarkan mereka ini generasi "Just-Do-It-(Yourself)". Mereka cenderung memilih naratif alternatif yang terkeluar dari trend filem arus perdana. Mereka menggunakan medium digital bukan sahaja dalam pembikinan, malah mengumpul dana, mempromosi, dan pemasaran.

Untuk era ini, kami memilih pembikin filem era digital dari latar belakang bukan Melayu iaitu Namewee (Wong Meng Chee). Filem yang dipilih adalah Nasi Lemak 2.0 (2011) yang juga filem pertama Namewee. Filem ini dihasilkan selari dengan dasar nasional Malaysia yang baharu iaitu 'Dasar 1Malaysia' (Yan, 2011). Filem ini menarik perhatian dan menjadi kontroversi kerana skrip filem ini tidak mencapai 70 peratus penggunaan bahasa Melayu dan beberapa isu lain yang dianggap tidak selari dengan idea nasionalisme Malaysia. Namun, ada yang berpendapat filem ini sebenarnya mempromosikan kepelbagaian etnik yang wujud bersama (coexist) di Malaysia (Ibid, 2011). Sekiranya sebelum ini pemaparan budaya dan identiti di Malaysia seringkali dikritik sebagai pseudo-budaya akibat pemaksaan dasar-dasar nasionalisme yang condong ke arah etnosentrik Melayu, era digital membuka ruang kepada karyawan generasi terkini memberi reaksi balas yang provokatif dan agresif. Namewee menggunakan sepenuhnya teknologi digital melalui media sosial atas talian seperti Youtube untuk mendapat sokongan dan membuat 'kesedaran' dalam kalangan masyarakat selain menjadi alat menekan secara halus keputusan berkaitan yang dilihat sebagai menjaga kepentingan politik pihak tertentu. Secara tidak langsung filem ini memaparkan realiti dan cabaran-cabaran mengetengahkan nilai dan budaya Malaysia yang kompleks.

\section{PENDEKATAN PERBINCANGAN}

Penulisan ini mengaplikasikan pendekatan "analisis wacana" (Discourse Analysis) sambil memberi penekanan kepada konsep "merantau" yang memangkin mobiliti individu dan sosial rantau ini. Sebagai pengukuhan, analisa dan perbincangan kami juga meminjam idea "budaya air" (Water Culture) seperti yang dibincangkan oleh Boomgard (2007) dan Andaya (2018) bersekali dengan konsep "pasang surut" (Tidalectics) budaya bagi mengupas isu sejarah, budaya dan representasi dalam Sinema Malaysia yang kompleks.

Di dalam arena akademik, kaedah analisis wacana mampu memberi pencerahan dalam menilai bagaimana kuasa sosial disalahguna, dominasi dan ketidakseimbangan terancang, dibincangkan dan ditentang melalui teks dan hujah di dalam konteks sosio-politik. Menerusi pengkajian yang menyanggah dasar-dasar rasmi seperti ini, analisis wacana mengambil pendekatan yang mendalam dan melakukan pendedahan yang akhirnya menentang ketidakseimbangan sosial (Van Dijk, 2001). Menurut Prince (1993), bidang kajian filem telah memberi penekanan terhadap wacana analisa teks (textual analysis) di antara "tanda-petanda" (signifier-signified) dalam mengkaji simbol dan simbolik yang arbitrari sejak 1970an.

Pendekatan ini membenarkan kupasan yang lebih kritikal dalam "membaca" sesebuah filem berbanding terjemahan makna simbolik yang simplistik. Sebagai contoh, kaedah ini digunakan oleh Hieng et al. (2020) dalam mengupas filem 29 Februari (2012) dan Ola Bola (2016) yang membincangkan aspek kepelbagaian budaya dalam Sinema Malaysia. Kajian Hieng et al. (2020) mendapati stereotaip ras masyarakat Cina di Malaysia masih jelas boleh dilihat dalam kedua-dua filem kajian. Stereotaip seumpama mempunyai kaitan dengan masalah persepsi seseorang individu terhadap individu lain di Malaysia yang menjadi masalah kepada pembangunan sebuah negara bangsa. 
Menurut Wang Gungwu (1985), "if we look closely at migration patterns throughout history, we will recognise that the spirit of merantau, which has operated in elitist in-migration and out-migration patterns, has been a valuable ingredient in human progress and has also been an integral part of Southeast Asian history." Dalam masyarakat Malaysia, konsep merantau yang mempunyai berbagai aspek dan ciri berbeza memberikan rasa termilik terhadap tempat dan tanahair yang kompleks. lanya tidak semudah peletakan label tertentu seperti migran, pendatang tanpa izin atau pelarian yang menjadi kebiasaan di negara ini. Istilah 'merantau' atau 'rantau' yang dipinjam dari masyarakat Minangkabau bermaksud "pantai" (coastal) atau "kawasan luar" (outer-area) dan menurut Harvey (2007), merantau adalah suatu konsep mobiliti yang menarik kerana aspek fleksibiliti dan perhubungan seseorang. Harvey mencadangkan merantau tidak mempunyai arah yang tetap kerana seseorang itu boleh terus menetap atau; berada di sesuatu tempat pada sesuatu masa atau; kemudiannya pulang. Menurut Carling dan Schewel (2018) pula, merantau adalah mengenai siapa diri individu itu dan berkaitan identiti. Menerusi pemaparan watak perantau dalam filem-filem pilihan, kami mencadangkan bahawa representasi sedemikian memaparkan kecairan yang berkaitan sesuatu tempat, individu dan budaya, yang boleh dilihat sebagai berada dalam keadaan "di antara" (in-betweeness) dan menjelaskan sifat berada dalam keadaan transisi dan hibrid (Bhabha, 1996).

Malaysia sebagai sebahagian daripada rantau se-budaya Nusantara bergantung kepada unsur air yang memangkin mobiliti sosial dan ekonomi. Kisah gemilang masa lampau dan kemajuan di Singapura kini, di mana kedudukan geografi yang meletakkan wilayah ini dipertengahan lebuhraya lautan perdagangan telah banyak dihujahkan (lihat Evers, 1988, 2014; Andaya \& Andaya, 2014; Sutherland, 2007). Menurut Boomgard (2007), kita amat dekat dengan air tidak kira di lautan mahupun di daratan seperti hujan yang membasahi bumi sepanjang tahun dan, kita kini boleh menyaksikan perkembangan "budaya air" yang baharu. Untuk penulisan ini, filem-filem yang dipilih memperlihatkan pasang surut dari interaksi yang wujud di antara faktor-faktor sosial, politik dan budaya yang terkesan dengan arus perubahan kemodenan dunia. Walaubagaimanapun, menurut Andaya (2016), "budaya air" ini mempunyai sifat naik turun, berubah-ubah atau pasang surutnya.

Menurut DeLoughrey (2007), pasang surut (Tidalectics), adalah dinamika dan anjakan perhubungan antara tanah dan lautan yang membenarkan kesusasteraan (dalam kajian ini filem dianggap sebagai sastera moden) mengupas isu ruang dan sejarah yang kompleks. Sebagai contoh, Perera (2009) menggunakan pendekatan pasang surut dan arus bagi mengupas permasalahan pendirian 'insular' di Australia. Menurut Perera, benua Australia secara berterusan telah dibentuk oleh pasang surut serta dipengaruhi oleh sifat lautan dan pantai di sekelilingnya yang membentuk karakteristik negara Australia sebagai entiti nasional. Seperkara yang jelas, beliau mengetengahkan perhubungan budaya berteraskan air di antara benua kepulauan berkenaan dengan 'Kepulauan Indo-Malaysia' yang juga dikenali sebagai kepulauan penduduk yang berorientasikan lautan. Identifikasi yang dipinjam oleh Boomgard (2007) dari pakar budaya Yuriko Nagata ini dilihat bersesuaian kerana kami membawa hujah bahawa pasang surut budaya negara ini boleh difahami melalui representasi masyarakat yang mengetengahkan isu ruang budaya dengan aspek mobiliti sosial dan perubahan sifat kepunyaan atau rasa termilik dalam filem-filem pilihan. Menurut Pugliese (2011) pula, sejarah dari perspektif antara wilayah (transregional) sedemikian jelas tidak dibincangkan dan direpresentasikan terutamanya di Australia. Bagi kami, Malaysia juga mempunyai isu yang sama di mana kaitan dan evolusi kebudayaan dan pembangunan antara negara seperti disenyapkan. Masyarakat Malaysia masih muda, masih agak jauh untuk menjejaki 100 tahun. 
Pasang surut kebudayaan yang berlaku sepanjang lebih 60 tahun sebagai sebuah entiti nasional juga seperti dilupakan.

Budaya dan identiti sosial seperti pasang surut dan arus lautan di mana setiap satunya mempunyai pendorong yang tertentu. Arus sosial, seperti yang dibincangkan boleh dirujuk sebagai kesedaran secara kolektif yang boleh menyerlahkan identiti budaya dan sifat kepunyaan atau rasa termilik pada satu kumpulan masyarakat yang sama. Bagi memerhatikan perubahan sosial di negara ini, perbincangan ini percaya bahawa kita tidak perlu menjejaki sejauh era kerajaan lampau (Srivijaya, Majapahit, Melaka) kerana apa yang telah berlaku semenjak perancangan penubuhan entiti nasional di pertengahan abad yang lalu hingga kini adalah memadai. Pembahagian filem-filem dari tiga era bagi perbincangan ini juga akan diselarikan dengan perubahan sosio-politik yang menjadi penanda kepada perubahan arus sosio-budaya Persekutuan Tanah Melayu, Malaya, dan Malaysia. Sehingga kini, representasi secara sinematik jelas menyumbang kepada kestabilan pembangunan nasional melalui pemaparan tertentu yang memangkin perdebatan umum yang semakin diraikan.

\section{i. $\quad$ Era hitam-putih - Sri Mersing (1961)}

\section{SINEMA MALAYSIA DALAM TIGA ERA}

Merantau adalah suatu konsep mobiliti serantau yang jelas dikongsi oleh berbagai kumpulan masyarakat Nusantara. Konsep ini menjadi tunjang kepada naratif Sri Mersing dan, di samping itu, filem ini mempamerkan bahawa pergerakan manusia dari satu wilayah ke wilayah yang lain dalam rantau ini bergantung kepada penerimaan dan rasa termilik dalam sesuatu komuniti. Selain itu, ruang budaya yang diperkatakan dan ditandai di dalam filem ini juga melangkaui sempadan nasional. Filem ini dipertontonkan kepada umum selari dengan tempoh waktu transformasi dari sebuah Persekutuan ke sebuah entiti nasional Malaya dan seterusnya sebagai Malaysia yang membawa kepada Konfrontasi Malaysia-Indonesia. Persoalan identiti watak-watak yang menentukan perjalanan plot penceritaan filem ini seperti sebuah refleksi untuk penontonan era berkenaan. Sri Mersing menurut Norman (2013), mengetengahkan isu kelas, prasangka terhadap wilayah-kawasan, dan diskriminasi.

Filem ini mengisahkan Damak, Deli, dan ibu mereka yang merantau ke sebuah penempatan yang dipanggil Mersing. Pada awalnya mereka diterima dengan baik, lebih-lebih lagi dengan perwatakan Damak yang produktif dan berpekerti. Namun, apabila gadis pujaan ramai yang bernama Sri menyatakan kasihnya kepada Damak secara umum beliau mengundang kemarahan anak lelaki Ketua Kampung yang menaruh hati kepadanya. Damak dan keluarganya dianiaya hingga mereka diminta meninggalkan Mersing. Walaupun filem ini berakhir dengan meletakkan yang baik harus menang, yang salah memohon kemaafan, Damak nekad untuk meneruskan kehidupan di tempat lain.

Mungkin tidak keterlaluan jika kami katakan Sri Mersing secara tidak langsung mencadangkan kepada penonton bahawa isu berkaitan penerimaan atau penolakan dalam sesuatu komuniti oleh kumpulan tertentu tidak hanya berkait rapat dengan aspek kuasa sosial dan individu tetapi juga bersangkutan dengan sikap dan keupayaan penduduk terhadap mobiliti. Lokaliti di mana tanah tempat tinggal penduduk secara semula jadinya dikelilingi air yang menjadi "lebuhraya" terbuka kepada semua untuk merantau dari satu tempat ke satu tempat lain.

Filem ini dimulakan dengan pemaparan dan pengisian yang berteraskan mobiliti (merantau) dan ruang (tempat). Lokasi pertama adalah sebuah pantai, tempat di mana tanah dan air bertembung. lanya seperti memberi penekanan kepada konsep tanahair yang dikongsi 
bersama oleh penduduk serantau. Pak Malau dan anaknya Sri mendarat dengan perahu dengan syot yang sangat luas (long shot). Mereka bergerak keluar dari syot berkenaan dan disunting dengan saiz syot yang sama menunjukkan perjalanan mereka melalui kawasan kebun kelapa. Mereka bertegur-sapa dengan Damak dan di sini Pak Malau menjelaskan kepada yang lain yang beliau dari kampungnya di Pulau Tioman. Kesinambungan perjalanan mereka terhenti di persimpangan jalan apabila mereka bertemu dengan Awang anak Ketua Kampung di mana penonton dijelaskan yang beliau baru pulang dari Terengganu setelah bertahun merantau. Naratif filem ini dibuka bagi memberi pengenalan terhadap subjektiviti dan perwatakan setiap individu tetapi menekankan kaitan tempat-tempat lain dengan penempatan tersebut. Dalam erti kata lain, ruang yang mereka diami dibina dengan baik melalui kaitannya dengan lokasi lain melalui pergerakan individu dari berbagai lapisan dan latar masa.

Persoalan ruang dan sikap kepunyaan yang membawa kepada penolakan atau penerimaan dalam komuniti amat jelas dalam naratif Sri Mersing. Filem ini juga seperti merumuskan bahawa asal-usul individu seperti tidak penting berbanding nilai-nilai kemanusiaan yang baik. Keluarga Damak dipinggirkan dan dihalau dari Mersing hanya kerana Damak diminati dan alasan yang mereka bukan "orang tempatan" mengukuhkan rasional tuduhan negatif yang dilemparkan kepada mereka.

Persoalan identiti Damak menjadi persoalan besar dalam naratif filem ini. Walaupun konflik berkembang apabila Sri mengakui yang beliau menaruh hati kepada Damak dan tidak mahu menerima Awang sebagai pasangan hidupnya. Pengarah pada awalnya meraikan kehidupan bermasyarakat melalui babak majlis perkahwinan yang memperlihatkan semangat tolong-menolong antara penduduk Mersing. Namun, syot-syot yang padat dengan watakwatak tertentu itu kemudiannya dikosongkan melalui pembahagian dua kumpulan iaitu di antara keluarga Damak dan penduduk yang terpengaruh dengan fitnah yang dilemparkan oleh Awang yang juga anak kepada Penghulu.

Watak Damak sebenarnya berada di antara konflik setempat, beliau cuba untuk menghindarkan diri dari konflik dengan Awang tetapi Sri merayu agar beliau dibantu. Di bahagian akhir filem ini, Damak dan Awang sama-sama menunjukkan rasa termilik yang berbeza. Awang bangga sebagai "anak Mersing," dan Damak menerima cabaran sebagai "anak Pahang." Persoalan identiti dalam filem ini juga kompleks, walaupun naratif "orang asing/luar" dimainkan oleh Awang, Sri juga pada awalnya telah dijelaskan bukan penduduk asal Mersing. Rasa termilik kepada sesuatu tempat seperti Mersing mula menjadi persoalan apabila rasa kepunyaan terhadap sesuatu yang tidak jelas (dikesan menerusi hajat Awang mengahwini Sri) dicabar oleh kebenaran (merujuk kepada penolakan Sri terhadap Damak).

Filem ini walaupun berada di penghujung kegemilangan filem hitam-putih, ianya disajikan kepada khalayak bersesuaian dengan keadaan di mana persoalan identiti nasional, rasa termilik kepada sesebuah institusi kenegaraan yang masih kabur. Mengambil kira penontonan filem pada era ini yang tertumpu di bandar-bandar, pandangan Barnard (2005) yang membincangkan filem-filem Melayu era 1950an dan 1960an boleh menjelaskan keperluan ini. Beliau mencadangkan ketika itu,

[i]n large urban centres like Singapore the new migrants had to deal with a vast amount of change, much of it resulting in destruction of the institutions, neighbourhoods, and cultural practices with which they were comfortable. 
Arus perubahan yang dipersembahkan menerusi konflik dalam naratif Sri Mersing ini berlaku selari dengan keperluan membangunkan entiti nasional yang masih agak asing kepada kebanyakan individu yang berada di tanahair ini. Menurut Faaland (2005) pula, orang Melayu pada era ini berhadapan dengan "perbezaan menonjol dari segi cara hidup yang mereka mampu, antara kedermawanan sultan-sultan yang memerintah dan keluargakeluarga mereka dengan kehidupan biasa orang Melayu di kampung-kampung". Perubahan arus yang dinyatakan sebagai "perbezaan tradisional dan diterima" oleh Faaland ini "jarang dibangkitkan sebagai isu politik yang serius".

\section{ii. $\quad$ Era independen - Keluarga Si Comat (1975)}

Seperti filem Seri Mersing, Keluarga Si Comat arahan Aziz Sattar ini turut menekankan konsep merantau atau 'penghijrahan' dan seperkara yang menarik adalah ianya berlaku pada fasa yang agak spesifik dalam konteks sosio-politik Malaysia. Konsep 'penghijrahan' diterjemahkan melalui kisah kehidupan Pak Comot dan anaknya Comat dari Kota Kinabalu ke ibukota Kuala Lumpur untuk mengubah status sosio-ekonomi mereka seperti yang digagaskan oleh peneraju politik Malaysia ketika itu. Arus perubahan dalam filem ini berbeza dengan Sri Mersing kerana ianya ditandai dengan aspek mobiliti masyarakat dari latar luar bandar ke bandar, dari gaya kehidupan tradisi kepada memenuhi tuntutan modeniti dan, naratif politik popular semasa.

Sinematografi filem ini menekankan aspek ruang yang diisi dengan representasi imejimej yang dirakam melalui pendekatan dalam bentuk atau gaya dokumentari. Penggunaan syot yang luas seperti long shot menjelaskan perbezaan di antara kemunduran kehidupan di pinggir bandar Kota Kinabalu dan kemodenan Kuala Lumpur. Bangunan pencakar langit, rumah yang besar, padang golf mengisi ruang landskap Kuala Lumpur sepanjang penceritaan filem ini.

Di samping itu, penghijrahan masyarakat turut dikaitkan dengan isu asimilasi. Sebagai contoh, gaya kehidupan masyarakat Melayu moden pada waktu ini ditandakan melalui cara hidup moden yang menuntut kemewahan harta dan kepuasan material. Gambaran ini jelas dipaparkan melalui perbezaan penggunaan kasut di dalam rumah, memiliki pembantu rumah bagi melakukan urusan domestik dan keperluan pemandu peribadi. Turut diselitkan elemen feminisme yang mana, wanita-wanita Melayu pada waktu ini tidak lagi melakukan kerja-kerja domestik. Sebaliknya wanita-wanita Melayu mula keluar mencari pekerjaan dan mampu berdikari. Orang-orang kaya Melayu seperti watak Borhan dan Syamsul juga diperlihatkan tidak kekok untuk sama-sama bekerja sama dengan usahawan senegara dari etnik Cina.

Kami ingin mencadangkan, pasang surut budaya merujuk kepada aspek perubahan dalam ruang lingkup mobiliti etnik Melayu untuk berubah daripada satu tahap kepada satu tahap yang lebih baik. Dalam konteks ini, Pak Comot dan Comat membuat keputusan mudah tanpa sebarang konflik untuk meninggalkan tempat kelahiran apabila mendapat tawaran daripada Borhan untuk memulakan kehidupan baru di Kuala Lumpur. Naratif ini juga dapat dikesan dalam konteks yang lebih luas, iaitu sebagai pengukuhan penubuhan Malaysia yang baru melepasi dekad yang kedua melalui filem. Filem ini memainkan peranan yang tersendiri dan mempromosikan 'Malaysia' sebagai entiti nasional yang kukuh walaupun masih baharu pada ketika itu.

Melalui ruang landskap yang dipaparkan dalam filem ini, konsep merantau menerusi penghijrahan individu diaplikasikan bagi mengangkat status golongan Melayu moden Malaysia. Imej-imej yang mengambarkan kemodenan dan kejayaan golongan Bumiputra 
Melayu lakonan Deddy M. Borhan mengaburi komposisi etnik Sabah yang sebenar. Etnik Melayu di Sabah, mahupun Borneo, adalah minoriti jika dibandingkan dengan etnik majoriti seperti Kadazandusun dan Iban. Selain itu, konsep ketuanan Melayu dan keinginan pemilikan terhadap golongan bawahan seperti yang digambarkan dalam babak Comat berangan untuk memiliki pemandu peribadi saling berkait (intertwined) dengan cara hidup moden yang dicanangkan melalui dasar-dasar nasional Malaysia pada ketika itu.

Kesimpulannya, berdasarkan pembacaan kami, aspek mobiliti melalui proses penghijrahan atau merantau, serta kejayaan Bumiputra Melayu dipermasalahkan melalui penterjemahan dari sudut material, simbol-simbol superfisial dan kecanggihan infrastruktur moden yang diambil dari kerangka nasionalisme luar yang dipinjam dari Barat. Selain itu, tidak keterlaluan dikatakan, Keluarga Si Comat menjadi penanda aras dan pembukaan kepada konsep nasionalisme yang sepatutnya berteraskan 'jati diri' Bumiputera Melayu seperti yang digembar-gemburkan. Namun sebaliknya, naratif filem ini menggambarkan modenisasi ala Barat yang berteraskan kapital. lanya menuntut "budaya Melayu" melalui proses asimilasi budaya dan acculturation (pembudayaan). Jati diri "budaya Melayu" jelas berdepan dengan pertembungan cara hidup yang berbeza.

Kehidupan yang dipaparkan dalam filem ini juga mewujudkan 'permasalahan' kepada imej dan jati diri Melayu yang tidak bersifat tetap. Sebaliknya berubah mengikut arus masa, selain pasang surut politik demokrasi moden yang dipraktikkan di Malaysia. Dalam kata lain, walaupun kebangkitan era ini lebih terarah kepada kebangkitan industri perfileman yang beteraskan etnik, filem-filem yang dihasilkan pada era ini lebih banyak meraikan proses asimilasi cara kehidupan masyarakat Melayu yang berubah-ubah, cair dan merupakan satu transisi yang bersifat 'sementara'.

\section{iii. Era digital - Nasi Lemak 2.0 (2011)}

Filem ini mengisahkan seorang pakar masakan muda berketurunan etnik Cina Malaysia yang bernama Huang. Beliau bercita-cita untuk menguasai masakan asli etnik Cina. Huang sangat menyanjungi tradisi masakan tradisi kumpulan masyarakat etnik Cina sehingga berusaha mempelajari seni kulinari di negara China. Apabila pulang ke Malaysia, beliau membuka restoran masakan Cina namun gagal mendapat sambutan kerana pelanggan di Malaysia lebih menggemari masakan yang mempunyai citarasa tempatan. Hal Ini dapat dilihat dalam babakbabak awal filem ini di mana seorang pelanggan yang datang ke restorannya meminta diletakkan sambal ke dalam nasi goreng yang dimasak oleh Huang. Ini menimbulkan rasa tidak puas hati kepada Huang yang sangat tegas dengan prinsip menjaga keaslian resipi masakan tersebut. Beliau menerima tamparan hebat apabila pelanggannya bertindak keluar dari restoran untuk meminta sambal nasi lemak dari gerai berhampiran yang diusahakan oleh Nor.

Huang diperlihatkan sebagai watak yang rasis dan memandang rendah akan nilai kebudayaan etnik lain apabila membuang bungkusan nasi lemak Nor kerana menganggap makanan itu tiada nilai dan tidak setanding masakan beliau yang terhasil dari budaya ribuan tahun masyarakat Cina. Sewaktu Huang cuba mengganggu gerai milik Nor, beliau terkejut kerana Nor mewarisi seni Tai Chi. Ini membuatkan Huang berubah fikiran kerana tidak menyangka etnik lain mampu menguasai seni budaya etnik Cina lebih baik dari beliau.

Restoran milik Huang akhirnya ditutup kerana tidak mendapat sambutan. Dia terpaksa memohon kerja memasak di restoran lain namun ditolak kerana tidak mengetahui masakan tempatan. Apabila hampir mengalah, beliau diberikan peluang kedua untuk meneruskan apabila bertemu dengan Qiao K, iaitu watak heroin yang memujuk Cef Huang mewakili keluarga beliau dalam satu pertandingan memasak bagi mendapatkan semula hak ke atas 
restoran warisan yang dirampas secara salah oleh Ibu saudara sendiri. Huang dengan bantuan Qiao K bertemu Nor yang memberi cadangan agar Huang berjumpa beberapa pakar dalam masakan tempatan. Huang dan Qiao K memulakan perjalanan bertemu dengan pakar masakan dari berbagai etnik Malaysia yang lain seperti Peranakan, India, dan Melayu yang akhirnya memberi kesedaran kepada beliau mengenai kepelbagaian nilai budaya negaranya sendiri.

Seperti yang terdapat di dalam filem-filem yang dibincangkan di atas, konsep 'merantau' juga jelas dalam Nasi Lemak 2.0 ini. Apabila Huang ingin mempelajari cara memasak tempatan yang baik, Nor telah menganjurkan beliau mengembara mencari ilmu masakan tersebut. Dalam pengembaraan, Huang bertemu dengan pelbagai manusia dari pelbagai latarbelakang yang ada di Malaysia. Mereka ini dipaparkan mempunyai keunikan namun mempunyai semangat kebersamaan sebagai warganegara yang tinggi. Huang akhirnya ditemukan dengan siapa sebenar dirinya, yang sebelum ini keliru dan diperlihatkan mempunyai masalah identiti. Sebagai generasi diaspora, Huang turut mengungkap kata, "siapakah aku sebenarnya"? Dialog ini diluahkan ketika Huang merasakan bahawa dirinya tidak seperti etnik Cina lain yang berasal dari "Tanah Besar" mereka kerana beliau bukan sahaja sentiasa ditewaskan pesaingnya Lan Qiao, seorang Cina dari Tanah Besar China malah, perubahan pandangan dan prinsip diri yang amat menyanjungi ketulenan budaya Cina di Malaysia tidak dikongsi sebahagian besar watak-watak dari etnik yang sama di sekelilingnya.

Selain itu, filem ini juga secara sinikal mengetengahkan isu etnik Cina yang merantau di negara ini. Perkara ini secara metaforanya diterjemahkan dari judul filem ini sendiri. Nasi lemak itu adalah metafora asimilasi budaya di Malaysia. Ianya makanan pelbagai kumpulan masyarakat di Malaysia walaupun dikatakan dibawa oleh etnik India ke rantau ini. '2.0' pula sering dilihat sebagai versi baru. Apa yang ingin dikemukakan oleh Namewee selaku pengarah adalah idea baru dalam hubungan antara etnik dan suku kaum di Malaysia.

Di sebalik kontroversi bahasa atau dialog di dalam filem yang tidak menggunakan 'Bahasa Kebangsaan' sepenuhnya, naratifnya menyentuh realiti sebenar keadaan perhubungan kaum di Malaysia. Komedi membolehkan watak-watak dipaparkan secara humor dan satira. Namewee menyentuh hampir kesemua aspek permasalahan tentang identiti dan karakteristik sebenar nasional Malaysia yang majmuk secara ringan dan sinikal. Watak Huang sendiri ditunjukkan sebagai memandang rendah akan budaya kumpulan etnik lain serta enggan menerima asimilasi dan merasa selesa dengan identiti Cina yang dibawanya. Namewee juga tidak berselindung menunjukkan adanya ahli masyarakat Cina Malaysia yang tidak menggunakan dialek Cina dan lebih selesa berbahasa Inggeris.

Walaupun stereotaip di dalam filem ini bermain dengan isu hubungan antara etnik yang sensitif, Namewee agak berani bermain dengan stereotaip etnik-etnik lain seperti masyarakat India dan Melayu Malaysia melalui watak "pakar kari" dari etnik India yang sentiasa cerewet dan sangat menjaga perhubungan keluarga serta, watak nelayan dari etnik Melayu yang mengamalkan poligami walaupun kurang berkemampuan dari sudut ekonomi.

Selain itu pertembungan sikap masyarakat diaspora terhadap isu diskriminasi dan sentimen warga kelas kedua dipaparkan dalam beberapa babak. Antaranya isu pendidikan, yang disentuh secara santai dan bersadur humor. Dalam masa yang sama, watak Huang juga melakukan tindakan terhadap perkerja asing seperti warga Nepal yang dipanggilnya sebagai Bangla - istilah yang sering dilabelkan kepada warga Bangladesh bagi menunjukkan bahawa mereka "orang asing". Secara tidak langsung, Namewee menunjukkan bahawa pendatang asing yang bekerja buruh dan keselamatan itu bertaraf lebih rendah dari warganegara. 
Terdapat kepelbagaian bentuk dan karakter dipaparkan walaupun ada yang disentuh secara superfisial. Watak Nor adalah seorang wanita Melayu yang mempunyai anak angkat dari etnik Cina selain mahir dengan seni Tai Chi. Selepas Namewee, semakin ramai karyawan dari etnik lain yang semakin galak menghasilkan filem di Malaysia tanpa merujuk panduan yang dikelaskan oleh Perbadanan Filem Nasional Malaysia (FINAS), dan berani mengambil risiko untuk tidak terikat dengan polisi-polisi bagi filem tempatan yang ditunjangi agensi tersebut.

\section{PENUTUP}

Secara rumusannya, perbincangan kami tidak bercadang untuk menetapkan kriteria khusus untuk klasifikasi 'nasional' bagi filem-filem dari sinema Malaysia. Apa yang diketengahkan adalah penelitian terhadap perubahan budaya masyarakat melalui persembahan sinematik seperti yang dipaparkan dan dibaca dari filem-filem pilihan. Selain itu, mobiliti budaya menerusi merantau dalam tempoh tiga era ini memperlihatkan proses kemenjadian masyarakat dalam konteks Malaysia sebagai sebuah entiti nasional. Bagi kami, persoalan identiti budaya nasional Malaysia dikaburi oleh naratif dan kuasa politik selain dari warga yang mewarisi penyelewengan istilah yang menjadi penyumbang utama kepada permasalahan erti identiti bangsa, etnik, dan suku kaum yang menyokong pembinaan negara.

Penulisan ini mencadangkan kecairan dan identiti budaya Malaysia dalam filem-filem tempatan boleh dibaca secara sinematik dengan mempertimbangkan arus perubahan budaya nasional secara kritis. Umumnya, idea autonomi budaya nasional tidak sesuai untuk diaplikasikan pada filem-filem Malaysia. Persoalan rasa termilik dan kepunyaan antaranya menjadi teras dalam naratif yang dibawa oleh Sri Mersing dan Nasi Lemak 2.0. Bagi Keluarga Si Comat pula, filem ini memberi refleksi kepada kebangkitan etnosentrik Melayu dalam pembentukan dasar-dasar politik Malaysia pasca konflik antara kaum di hujung 1960an.

\section{BIODATA}

Mohd Erman Maharam berjinak dengan kerja-kerja kamera pada 1993 dan melangkah ke penerbitan filem cereka sebagai sinematografer selepas menamatkan program ljazah Pertama di UiTM dan ljazah Sarjana di Griffith University. Telah berkhidmat di UiTM sejak 2005, dan kajian ljazah Kedoktoran beliau di University of Nottingham membincangkan transnationalisme dalam sinema Malaysia, Indonesia, dan Singapura. E-mel: erman@uitm.edu.my

Mastura Muhammad merupakan pensyarah kanan di Fakulti Filem, Teater dan Animasi, UiTM. Dalam Pengajian Filem, Mastura menumpukan perhatian kepada Sinema Malaysia dengan sub-kepakaran kajian terhadap topik berkaitan persoalan gender, feminisme, Islam dan rentas budaya. E-mel: masturafita@gmail.com

Harith Baharudin berkongsi minat dan kecintaannya terhadap bidang filem di Fakulti Filem, Teater dan Animasi, UiTM. Berkelulusan Sarjana Pengajian Filem dari Universiti Sains Malaysia, dan masih bergiat aktif sebagai seorang karyawan filem. E-mel: aresbahar@gmail.com 


\section{RUJUKAN}

Andaya, L. Y. (2018). Water in the study of Southeast Asia. Kemanusiaan: The Asian Journal of Humanities, 25.

Andaya, B. W., (2016). Rivers, oceans, and spirits: Water cosmologies, gender, and religious change in Southeast Asia. TRaNS: Trans-Regional and-National Studies of Southeast Asia, 4(2), pp. 239-263.

Andaya, B. W., \& Andaya, L. Y. (2014). The "Sea of Malayu". In D. Jones, \& M. Marion (Eds.), The dynamics of cultural counterpoint in Asian studies (pp. 207-219). Albany: State University of New York.

Anderson, B., (1983). Imagined communities: Reflections on the origin and spread of nationalism. London: Verso.

Anwar, R. (1988). The Indonesian film industry. Media Asia, 15(3), 134-7.

Asiah Sarji. (2006). Malaysian national cinema: An identity crisis?. Jurnal Skrin Malaysia, 3, 143-154.

Barnard, T. P. (2005). Sedih sampai buta: Blindness, modernity and tradition in Malay films of the 1950s and 1960s. Bijdragen tot de taal-, land-en volkenkunde/Journal of the Humanities and Social Sciences of Southeast Asia, 161(4), 433-453.

Barnard, T. P. (2010). Film Melayu: Nationalism, modernity and film in a pre-World War Two Malay magazine. Journal of Southeast Asian Studies, 41(1), 47-70.

Bhabha, H. (1990). Nation and narration. London: Routledge.

Bhabha, H. K. (1996). Culture's in-between. Questions of cultural identity, 1, 53-60.

Boomgaard, P. (2007). In a state of flux: Water as a deadly and a life-giving force in Southeast Asia. In P. Boomgaard (Ed.), A world of water: Rain, rivers and seas in Southeast Asian histories (pp. 1-26). Leiden: KITLV Press.

Harvey, S. S. (2007). Nomadic trajectories: Mapping short film production in Singapore. InterAsia Cultural Studies, 8(2), 262-276.

Chang, H.-N. (2017). Unfolding time to configure a collective entity: Alternative digital movies as Malaysian national cinema (Doctoral Dissertation, Ohio University). Retrieved from https://etd.ohiolink.edu/!etd.send_file?accession=ohiou1490956487498085\&disposi tion=inline

Cheng, K. G. (2007). Just-do-it-(yourself): Independent filmmaking in Malaysia. Inter-Asia Cultural Studies, 8(2), 227-247.

DeLoughrey, E. M. (2007). Routes and roots: Navigating Caribbean and Pacific island literatures. Honolulu: University of Hawaii Press.

Evers, H.-D. (1988). Traditional trading networks of Southeast Asia. Archipel, 35, 89-100.

Evers, H.-D. (2014). Governing maritime spaces: The South China Sea as a Mediterranean cultural area. South East Asian Research Centre, City University of Hong Kong Working Paper Series No. 152. http://dx.doi.org/10.2139/ssrn.2485748

Faaland, J. (2005). Dasar ekonomi baru: Pertumbuhan negara dan pencapaian ekonomi orang Melayu. Kuala Lumpur: Utusan Publications.

Fatimah Muhd Shukri, \& Nur Afifah Vanitha Abdullah. (2018). Sepet (2005): Sebuah filem nasional Malaysia. Jurnal Komunikasi: Malaysian Journal of Communication, 34(2).

Fuziah Kartini Hassan Basri, Asiah Sarji, \& Arfah Yusof. (2018). Era digital: Cabaran baru kepada karyawan serta pendidik penyiaran dan perfileman di Malaysia. Jurnal Komunikasi: Malaysian Journal of Communication, 20, 1-15.

Ghani, S. (Director). (1961). Sri Mersing [Motion Picture]. 
Gungwu, W. (1985). Migration patterns in history: Malaysia and the region. Journal of the Malaysian Branch of the Royal Asiatic Society, 58(1: 248), 43-57. Retrieved from http://www.jstor.org/stable/41493000

Harvey, S. S. (2007). Nomadic trajectories: mapping short film production in Singapore. InterAsia Cultural Studies, 8(2), 262-276.

Hatta Azad Khan. (1997). The Malay cinema. Bangi: Penerbit Universiti Kebangsaan.

Heide, W. v. (2002). Malaysian cinema, Asian films: National cultures and border crossings. Amsterdam: Amsterdam University Press.

Hieng, B. K., Hwa, S. P., \& Chee, B. C. (2020). Examining the portrayal of Chinese characters in Malaysian contemporary films using textual analysis: Two case studies. Asian Journal of Arts, Culture and Tourism, 2(2), 19-32.

Higbee, W. (2007). Beyond the (trans)national: Towards a cinema of transvergence in postcolonial and diasporic francophone cinema(s). Studies in French Cinema, 7(2), 7991.

Higson, A. (1989). The concept of national cinema. Screen, 30(4), 36-47.

Higson, A. (2000). The limiting imagination of national cinema. In M. Hjort, \& S. MacKenzie (Eds.), Cinema and nation (pp. 63-74). London and New York: Routledge.

Kahn, J. S. (2006). Other Malays: Nationalism and cosmopolitanism in the modern Malay world. Singapore: Singapore University Press.

Khoo, G. C. (2006). Reclaiming adat: Contemporary Malaysian film and literature. Vancouver: UBC Press.

Latif, B. (1989). The revival. In, Cintai Filem Malaysia/Love Malaysian films (pp. 49-52). Hulu Kelang: National Film Development Malaysia.

Levy, E. (1999). Cinema of outsiders: The rise of American independent film. New York and London: New York University Press.

Mahyuddin Ahmad, \& Lee, Y. B. (2015). Negotiating class, ethnicity and modernity: The 'Malaynisation' of P. Ramlee and his films. Asian Journal of Communication, 25(4), 408421.

Malik, K. (1996). The meaning of race: Race, history and culture in Western society. New York: NYU Press.

McKernan, B. (2005). Digital cinema: The revolution in cinematography, postproduction, and distribution. USA: McGraw-Hill.

Namewee (Director). (2011). Nasi lemak 2.0 [Motion Picture].

Norman Yusoff. (2013). Contemporary Malaysian cinema: Genre, gender and temporality (Doctoral dissertation, University of Sydney). Retrieved from https://ses.library.usyd.edu.au/bitstream/2123/9925/1/yusoff_n_thesis.pdf

Norman Yusoff. (2018, September 5). Discourse on Malaysian cinema. The Star Online, Retrieved from https://www.thestar.com.my/opinion/letters/2018/09/05/discourseon-malaysian-cinema/

Palfrey, J., \& Gasser, U. (2008). Generation internet. Die Digital Natives Wie sie leben-Was sie denken-Wie sie arbeiten. München: Hanse.

Perera, S. (2009). Australia and the insular imagination: Beaches, borders, boats, and bodies. New York and Hampshire: Palgrave Macmillan.

Prince, S. (1993). The discourse of pictures: Iconicity and film studies. Film Quarterly, 47(1), 16-28.

Pugliese, J. (2011). Australia and the insular imagination: Beaches, borders, boats, and bodies. Continuum, 25(1), 134-137. 
Sattar, A. (Director). (1975). Keluarga si comat [Motion Picture].

Scott, J. C. (2009). The art of not being governed: An anarchist history of upland Southeast Asia. New Haven and London: Yale University Press.

Suhana Saad, Ali Salman, Novel Lyndon, Selvadurai, S., Zaimah, R., Azima, A. M., \& Mohd Yusof Hussain. (2012). Krisis politik melayu dan pembinaan negara bangsa. Geografia: Malaysian Journal of Society and Space, 8(9), 39-45.

Sutherland, H. (2007). Geography as destiny? The role of water in Southeast a sian history. In P. Boomgaard (Ed.), A world of water: Rain, rivers and seas in Southeast Asian histories (pp. 27-70). Leiden: KITLV Press.

Syed Hussein Alatas. (1985). Nilai kebudayaan dan disiplin nasional. Dlm. Wan Abdul Kadir Yusoff, \& Zainal Abidin Borhan (pynt.), Ideologi dan kebudayaan kebangsaan (pp. 123135). Kuala Lumpur: Jabatan Pengajian Melayu, Universiti Malaya.

Van Dijk, T. A. (2001). 18 critical discourse analysis. The handbook of discourse analysis, 349371.

Wan Aida Wan Yahaya. (2011). Historical films and the Asian nations: Struggles for independence and emancipation - A gendered perspective (Doctoral Dissertation, Monash University). Retrieved from https://monash.figshare.com/articles/Historical_films_and_the_Asian_nations_strug gles_for_independence_and_emancipation_a_gendered_perspective/4597672

Yan, S. K. (2011, July 27). Namewee cooks up a laugh with Nasi Lemak 2.0. The Star Online, Retrieved

from https://www.thestar.com.my/lifestyle/entertainment/music/news/2011/07/27/nam ewee-cooks-up-a-laugh-with-nasi-lemak-20/

Zainal Keling. (1985). Konsep kebudayaan kebangsaan. DIm. Wan Abdul Kadir Yusoff, \& Zainal Abidin Borhan (pynt.), Ideologi dan kebudayaan kebangsaan (pp. 1-46). Kuala Lumpur: Jabatan Pengajian Melayu, Universiti Malaya. 